\title{
Effect of normothermic cardiopulmonary bypass on renal injury in pediatric cardiac surgery: A randomized controlled trial
}

\author{
Massimo Caputo, MD, ${ }^{\text {a,b }}$ Nish Patel, FRCS, ${ }^{\mathrm{b}}$ Gianni D. Angelini, FRCS, ${ }^{\mathrm{b}}$ Paolo de Siena, MD, ${ }^{\mathrm{a}}$ \\ Serban Stoica, FRCS, ${ }^{a}$ Andrew J. Parry, FRCS, ${ }^{a}$ and Chris A. Rogers, PhD $^{\mathrm{b}}$
}

Objective: Hypothermic cardiopulmonary bypass (CPB), although associated with a reduction in oxygen requirement, has a number of disadvantages including detrimental effects on enzymatic function, energy generation, and cellular integrity. Normothermic perfusion is potentially a more physiologic method to maintain the functional integrity of major organ systems. One of the aims of this trial was to compare the effect of normothermic and hypothermic CPB on renal injury in pediatric patients undergoing cardiac surgery.

\begin{abstract}
Methods: Fifty-nine children (median age, 78 months; interquartile range, 39-130) undergoing corrective cardiac surgery were randomized to either hypothermic $\left(28^{\circ} \mathrm{C}\right)$ or normothermic $\left(35^{\circ} \mathrm{C}-37^{\circ} \mathrm{C}\right) \mathrm{CPB}$. Urinary albumin, retinal binding protein (RBP) and $N$-acetyl- $\beta$-glucosaminidase (NAG) were measured preoperatively, end of $\mathrm{CPB}, 4$, and 24 hours postoperatively and were expressed as a ratio of urinary creatinine. Serum creatinine was measured preoperatively, end of $\mathrm{CPB}$, and 24 and 48 hours postoperatively. Results are expressed as a difference in means (normotheric - hypothermic) or as a ratio of geometric means (normothermic/hypothermic).
\end{abstract}

Results: Baseline characteristics were similar in both groups. For these biochemical markers no significant interactions between treatment and postintervention time were found. Serum creatinine $(-2.10 ; 95 \%$ confidence interval [CI], -6.51-2.31), RBP (ratio, 0.96; 95\% CI, 0.65-1.41), and NAG (ratio, 0.86; 95\% CI, 0.56-1.36) were similar in the 2 groups $(P \geq .34)$, but the urinary albumin was significantly lower in the normothermic group (ratio, $0.63 ; 95 \% \mathrm{CI}, 0.42-0.95, P=.03$ ).

Conclusions: Normothermic $\mathrm{CPB}$ is associated with similar renal impairment to hypothermic $\mathrm{CPB}$ in children undergoing heart surgery. (J Thorac Cardiovasc Surg 2011;142:1114-21)

Supplemental material is available online.

\section{Earn CME credits at}

http://cme.ctsnetjournals.org

The main rationale for body cooling during cardiopulmonary bypass (CPB) is to protect organs such as the brain, the kidneys, and the heart from ischemic injury by reducing

\footnotetext{
From Bristol Royal Hospital for Children ${ }^{\mathrm{a}}$ and Bristol Heart Institute, ${ }^{\mathrm{b}}$ University of Bristol, Bristol, United Kingdom.

The British Heart Foundation, NIHR Bristol Biomedical Research Unit in Cardiovascular Medicine and Garfield Weston Trust, supported this work.

Disclosures: Authors have nothing to disclose with regard to commercial support.

Read at the Ninety-first Annual Meeting of The American Association for Thoracic Surgery, Philadelphia, Pennsylvania, May 7-11, 2011.

Received for publication May 5, 2011; revisions received July 13, 2011; accepted for publication Aug 4, 2011; available ahead of print Aug 29, 2011.

Address for reprints: Massimo Caputo, MD, Bristol Royal Hospital for Children, Bristol, BS2 8BJ, United Kingdom (E-mail: M.Caputo@bristol.ac.uk).

0022-5223/\$36.00

Copyright (C) 2011 by The American Association for Thoracic Surgery doi:10.1016/j.jtcvs.2011.08.008
}

metabolic rate and oxygen consumption ${ }^{1}$ and decreasing the whole-body inflammatory response. ${ }^{2-4}$ However, the combined effects of hypothermia, nonpulsatile perfusion, and reduced mean arterial pressure cause release of angiotensin, renin, catecholamines, and antidiuretic hormones. ${ }^{5}$ These circulating hormones promote renal vasoconstriction, reduce total renal blood flow, and redistribute intrarenal blood flow to the renal medulla. Also, organ immaturity can result in a reduced glomerular filtration rate and medullary concentration ability. ${ }^{5}$ The limited uncontrolled clinical data available suggest that the risks of renal failure associated with normothermic and hypothermic CPB are comparable. ${ }^{6}$ Ip-Yam and associates ${ }^{7}$ demonstrated no difference in creatinine clearance, fractional sodium excretion, microalbuminuria, and urinary $N$-acetyl- $\beta$-D-glucosaminidase (NAG) after normothermic $\left(37^{\circ} \mathrm{C}\right)$ versus hypothermic $\left(28^{\circ} \mathrm{C}\right) \mathrm{CPB}$. In a randomized controlled trial in adults, our group $^{8}$ demonstrated that $\mathrm{CPB}$ perfusion temperature does not influence perioperative changes in serum markers of renal function and that normothermic CPB was not associated with an increased risk of postoperative renal failure.

CPB perfusion temperature strategies and their effects on organ function are largely the result of work carried out in adult humans ${ }^{6-9}$ or in animal models, ${ }^{2,3}$ and the conclusions drawn from those studies cannot necessarily be applied directly to infants or children. In a randomized 

Abbreviations and Acronyms
$\mathrm{CI}=$ confidence interval
$\mathrm{CPB}=$ cardiopulmonary bypass
ICU $=$ intensive care unit
$\mathrm{NAG}=N$-acetyl- $\beta$-D-glucosaminidase
$\mathrm{RBP}=$ retinal binding protein

controlled trial in infants and children undergoing cardiac surgery, we ${ }^{9}$ recently demonstrated that normothermic CPB was associated with reduced oxidative stress and similar myocardial reperfusion injury and inflammatory response compared with hypothermic CPB. In this report, from the same trial, we compare the effect of normothermic and hypothermic CPB on renal injury in children undergoing repair of simple congenital cardiac malformations.

\section{PATIENTS AND METHODS}

Fifty-nine children undergoing corrective cardiac surgery between $\mathrm{Au}-$ gust 2002 and September 2004 at the Bristol Royal Hospital for Children were randomized to receive either hypothermic $\left(28^{\circ} \mathrm{C}\right)$ or normothermic $\left(35^{\circ} \mathrm{C}-37^{\circ} \mathrm{C}\right) \mathrm{CPB}$. Neonates or patients requiring hypothermic circulatory arrest or complex repair of the pulmonary arterial system with periods of low-flow CPB were excluded from the study, as were patients with preexisting renal dysfunction. The study was approved by the Bristol Royal Hospital Ethical Committee and parental informed consent was gained for all patients. Random treatment allocations were generated by computer in advance of starting the study, using block randomization with varying block sizes. Allocation details were concealed in sequentially numbered, opaque sealed envelopes. Randomization was revealed to the surgeon after the start of the operation.

\section{Anesthetic and Surgical Technique}

Anesthetic technique was standardized as reported previously. ${ }^{9}$ Temperature was monitored via nasopharyngeal, rectal, and skin probes. On establishment of $\mathrm{CPB}$, the patient was either cooled to a target nasopharyngeal temperature of $28^{\circ} \mathrm{C}$ or maintained at $35^{\circ} \mathrm{C}$ to $37^{\circ} \mathrm{C}$ depending on randomization. Cold blood $\left(4^{\circ} \mathrm{C}-6^{\circ} \mathrm{C}\right) \mathrm{St}$ Thomas' Hospital I-based cardioplegic solution (4:1 dilution blood/St Thomas' Hospital I crystalloid cardioplegic solution) was used for myocardial preservation, with the following composition (in millimoles per liter): $16 \mathrm{MgCl}_{2}, 2 \mathrm{CaCl}_{2}, 20 \mathrm{KCl}, 147 \mathrm{NaCl}$, and 1.0 procaine $\mathrm{HCl}$. Additional cardioplegic solution was administered after each 20 minutes of aortic crossclamping. CPB flow was kept between 3.0 and $3.5 \mathrm{~L} \mathrm{~m}^{-2} \mathrm{~min}^{-1}$, and hematocrit values were maintained between $25 \%$ and $30 \%$. In the hypothermic group, rewarming was started just before removal of the aortic crossclamp. Patients were rewarmed with a temperature difference of $8^{\circ} \mathrm{C}$ at the level of the heat exchanger between the blood and the rewarming fluid. Rewarming took place in the normothermic group only if the temperature was less than $36^{\circ} \mathrm{C}$. A dopamine infusion was commenced in all patients at an initial rate of $5 \mu \mathrm{g} \cdot \mathrm{kg}^{-1} \cdot \mathrm{min}^{-1}$ before weaning from $\mathrm{CPB}$. Patients were weaned from $\mathrm{CPB}$ once the nasopharyngeal temperature had reached $36^{\circ} \mathrm{C}$.

After the operation, all patients were admitted to the pediatric intensive care unit (ICU) and were managed according to the unit protocols ${ }^{9}$ by intensivists and pediatric cardiologists blinded to the randomization.

\section{Outcome Variables}

End points were the release of urinary albumin, retinal binding protein (RBP), and NAG measured preoperatively, at the end of CPB, and 4 and
24 hours postoperatively. All urinary markers were also expressed as a ratio of urinary creatinine to adjust for variations in the glomerular filtration rate. Serum urea, creatinine, and electrolytes were measured preoperatively, at the end of CPB, and 24, 48, and 72 hours postoperatively. Serum levels of glucose, lactate, and hematocrit were also measured preoperatively, intraoperatively, and up to 24 hours postoperatively. We also recorded all-cause in-hospital mortality and morbidity as previously reported. ${ }^{9}$

\section{Study Size}

The study sample size for the trial was set at 29 patients per group. This sample size was based on our previous experience in similar studies on adult and pediatric patients ${ }^{4,9,10}$ in which we have been able to demonstrate differences for the total area under curves describing the levels of biochemical markers during the first 24 hours after surgery as 0.8 to 1.1 standard deviations. A study with 29 patients per group is sufficient to detect a difference between groups equivalent to 0.75 standard deviations (ie, about the minimum observed in our previous studies) or greater with $80 \%$ power at a $5 \%$ significance level (2tailed).

\section{Sample Collection and Analysis}

The urine samples were centrifuged at $1000 \mathrm{~g}$ for 5 minutes and the supernatants were stored at $-20^{\circ} \mathrm{C}$. Biomarkers were measured within 2 weeks after initial urine collection. Urinary NAG was measured by colorimetric assay by using a commercially available kit (Roche Applied Science, Indianapolis, Ind $)^{11}$ according to the manufacturer's protocol. Urinary RBP was analyzed using a very sensitive latex-enhanced immunoassay technique with nephelometric detection. ${ }^{12}$ Urinary albumin was measured using a turbimetric assay. The measured values were normalized to the urinary creatinine concentration. The measurements were made in duplicate and in a blinded fashion.

Serum and urine creatinine concentrations were measured by the Jaffé assay using Roche/Hitachi 917 systems (Roche Diagnostics, Indianapolis, Ind) and Creatinine Companion (Exocell, Philadelphia, Pa), ${ }^{13}$ respectively.

\section{Statistical Analysis}

Analyses were carried out on the basis of intention to treat. Continuous variables were summarized using the mean and standard deviation (or median and interquartile range if the distribution was skewed), and categorical data were summarized as a number and percentage. Crossclamp and CPB times were compared using the Wilcoxon rank sum test.

Continuous biomarker outcomes are compared between the hypothermic and normothermic CPB groups using a difference in means, with logarithmic transformations if distributions were skewed. For transformed data the results are transformed back to the original scale after analysis, with the treatment effect expressed as a ratio of geometric means. Repeated measures of continuous outcomes were analyzed using the linear mixed effects methodology, and the preoperative and postoperative values were modeled jointly to avoid the need to exclude or impute values for cases with missing preoperative values. Treatment by time interactions was examined and if the interaction was statistically significant at the $10 \%$ level using a likelihood ratio test, changes in treatment effect with time are described; otherwise, an overall treatment effect (pooled over the postintervention time points measured) is reported. The validity of the models fitted was assessed graphically.

Results are presented as effect sizes with $95 \%$ confidence intervals (CI). No correction has been made for multiple comparisons, but our interpretation of the findings takes into account the consistency of the associations observed and their magnitude, as well as their statistical significance.

Mixed models were fitted in SAS version 9.2 (SAS Institute, Inc, Cary, NC). All other analyses were performed using Stata version 11.1 (StataCorp LP, College Station, Tex). 
TABLE 1. Baseline characteristics

\begin{tabular}{|c|c|c|c|c|}
\hline & \multicolumn{2}{|c|}{$\begin{array}{l}\text { Hypothermic } \\
\text { CPB }(n=31)\end{array}$} & \multicolumn{2}{|c|}{$\begin{array}{c}\text { Normothermic } \\
\text { CPB }(n=28)\end{array}$} \\
\hline & $\begin{array}{c}\text { Median } \\
\text { or } \mathbf{n}\end{array}$ & IQR or $\%$ & $\begin{array}{c}\text { Median } \\
\text { or } \mathbf{n}\end{array}$ & IQR or $\%$ \\
\hline Age (mo) & 52 & $26-138$ & 90.5 & $42-127$ \\
\hline Male gender & 16 & 52 & 9 & 32 \\
\hline Cyanotic & 2 & 6 & 1 & 4 \\
\hline \multicolumn{5}{|l|}{ Indication } \\
\hline ASD & 10 & 32 & 12 & 43 \\
\hline VSD & 12 & 39 & 9 & 36 \\
\hline AV valve repair & 2 & 6 & 1 & 4 \\
\hline pAVSD & 4 & 13 & 1 & 4 \\
\hline RVOT repair & 3 & 10 & 0 & 0 \\
\hline PA reconstruction & 1 & 3 & 1 & 4 \\
\hline Pulmonary valvotomy & 0 & 0 & 1 & 4 \\
\hline PAPVD & 0 & 0 & 1 & 4 \\
\hline SubAS & 5 & 16 & 3 & 11 \\
\hline PVR & 1 & 3 & 0 & 0 \\
\hline TVR & 1 & 3 & 0 & 0 \\
\hline AoV repair & 1 & 3 & 0 & 0 \\
\hline Redo & 4 & 13 & 5 & 18 \\
\hline Body surface area $\left(\mathrm{m}^{2}\right)$ & 0.69 & $0.50-1.2$ & 0.90 & $0.65-1.12$ \\
\hline \multicolumn{5}{|c|}{$\begin{array}{l}\text { Data are number and percentage or median and interquartile range }(I Q R) \text {. CPB, Car- } \\
\text { diopulmonary bypass; } A S D \text {, atrial septal defect; } V S D \text {, ventricular septal defect; } A V \text {, } \\
\text { atrioventricular; } p A V S D \text {, atrioventricular septal defect; } R V O T \text {, right ventricular out- } \\
\text { flow tract; } P A \text {, pulmonary artery; } P A P V D \text {, partial anomalous pulmonary venous } \\
\text { drainage; } A S \text {, aortic stenosis; } P V R \text {, pulmonary valve repair; } T V R \text {, tricuspid valve re- } \\
\text { pair; } A o V \text {, aortic valve. }\end{array}$} \\
\hline
\end{tabular}

\section{RESULTS}

Thirty one patients were randomized to the hypothermic group and 28 to the normothermic group. Overall, the median age was 78 months (interquartile range, 39-130) with $42 \%$ male. Reasons for surgery included a predominance of atrial $(37 \%)$ and ventricular septal defects (33\%). There were 9 redo procedures (Table 1). As anticipated, lowest body and reperfusion temperatures were both significantly lower in the hypothermic group (both $P<.0001)$. Operative and clinical outcomes are reported in Table 2. Mortality and morbidity were similar across the 2 groups, as was the use of diuretics. Crossclamp and CPB times were lower in the normothermic group $(P=.001$ and $P=.03$, respectively).

Urinary albumin, RBP, and NAG were released in a timedependent fashion (Table 3 ). Urinary albumin concentration decreased after 4 and 24 hours from the end of CPB, and there was an increase of RBP and NAG levels over postintervention time in both groups, but there was no evidence to suggest time-related differences between the 2 groups when expressed as a ratio of urinary creatinine (test for time by treatment interaction, $P \geq .46$ ).

When the levels are expressed as a ratio of urinary creatinine, the urinary albumin was, on average, $37 \%$ lower in the normothermic group (ratio, 0.63 ; 95\% CI, 0.42-0.95; $P=.03$; Figure 1). In contrast, RBP was similar across
TABLE 2. Operative characteristics and clinical outcomes

\begin{tabular}{|c|c|c|c|c|}
\hline & \multicolumn{2}{|c|}{$\begin{array}{l}\text { Hypothermic } \\
\text { CPB }(n=31)\end{array}$} & \multicolumn{2}{|c|}{$\begin{array}{c}\text { Normothermic } \\
\text { CPB }(n=28)\end{array}$} \\
\hline & $\begin{array}{c}\text { Median } \\
\text { or } \mathbf{n} \\
\end{array}$ & $\begin{array}{c}\text { IQR or } \\
\% \\
\end{array}$ & $\begin{array}{c}\text { Median } \\
\text { or } \mathbf{n} \\
\end{array}$ & $\begin{array}{c}\text { IQR or } \\
\% \\
\end{array}$ \\
\hline Crossclamp time (min) & 32 & $27-49$ & 22 & $14.5-33$ \\
\hline CPB time (min) & 62.0 & $47-79$ & 48.5 & $39-66$ \\
\hline Lowest body temperature $\left({ }^{\circ} \mathrm{C}\right)$ & 28.2 & $28.0-28.6$ & 35.0 & $34.9-35.5$ \\
\hline In-hospital mortality & 0 & & 0 & \\
\hline Blood loss first $24 \mathrm{~h}(\mathrm{~mL})$ & 130 & $95-240$ & 160 & $127.5-267.5$ \\
\hline Fluid balance $(\mathrm{mL})$ & +46 & $-280-143$ & +34.75 & $-262.5-139$ \\
\hline \multirow[t]{2}{*}{ Red cell transfusion $(\mathrm{mL} / \mathrm{kg})$} & 8 & 29 & 8 & 29 \\
\hline & 9.5 & $6.8-16.6$ & 9.6 & $6.8-19.7$ \\
\hline \multirow{2}{*}{$\begin{array}{l}\text { Platelet/FFP transfusion } \\
\quad(\mathrm{mL} / \mathrm{kg})\end{array}$} & 5 & 18 & 6 & 21 \\
\hline & 5.2 & $4.9-5.5$ & 9.9 & $4.9-10.0$ \\
\hline Inotropic support & 24 & 77 & 17 & 61 \\
\hline Total $\left(\mu \mathrm{g} \mathrm{kg}^{-1} \min ^{-1}\right)$ & 18.2 & $11.8-38.3$ & 15.0 & $10.0-20.5$ \\
\hline Peak $\left(\mu \mathrm{g} \mathrm{kg}^{-1} \mathrm{~min}^{-1}\right)$ & 6.5 & 5-10 & 5.0 & 5-10 \\
\hline Duration $(\mathrm{h})$ & 20 & $14.5-24$ & 19 & $12-22$ \\
\hline Diuretic use & 4 & 13 & 1 & 4 \\
\hline $\begin{array}{l}\text { Postoperative ventilation } \\
\text { time (h) }\end{array}$ & 8 & $6-23$ & 8.5 & $6-21$ \\
\hline Postoperative hospital stay (d) & 5 & $5-7$ & 5 & $5-6$ \\
\hline
\end{tabular}

the 2 groups (ratio, $0.96 ; 95 \% \mathrm{CI}, 0.65-1.41 ; P=.8$; Figure 2). NAG was, on average $14 \%$ lower (ratio, 0.86 ; 95\% CI, 0.56-1.36; $P=.5$; Figure 3), but this difference was not significantly significant. With the exception of the urinary albumin/creatinine ratio, none of the differences was statistically significant (Figure 4).

Postoperative serum glucose, hematocrit, creatinine, urea, and electrolytes were, on average, lower in the normothermic group, but the differences observed between the 2 groups were not statistically significant $(P \geq .07$; Appendix E1). The serum creatinine and urea were reduced by $2.1 \mu \mathrm{mol} / \mathrm{L}(95 \% \mathrm{CI},-6.51$ to $2.31 ; P=.34)$ and $0.42 \mathrm{mmol} / \mathrm{L}(95 \% \mathrm{CI},-0.88$ to $0.04 ; P=.072)$, on average, respectively.

\section{DISCUSSION}

To the best of our knowledge, this is the first randomized trial to compare the effects of hypothermic and normothermic $\mathrm{CPB}$ on renal function in pediatric heart surgery. Our results suggest that, overall, normothermic CPB is associated with similar postoperative renal injury compared with hypothermic CPB. Both normothermia and hypothermia resulted in a significant release of urinary markers of kidney injury, with NAG and RBP levels remaining elevated up to 24 hours postoperatively. These markers are sensitive and reliable indicators of renal tubular injury early after cardiac surgery compared with conventional parameters such as blood urea and serum creatinine. ${ }^{14-16}$ 
TABLE 3. Biochemical markers

\begin{tabular}{|c|c|c|c|c|c|c|c|}
\hline & \multicolumn{2}{|c|}{$\begin{array}{l}\text { Hypothermic } \\
\text { CPB }(n=31)\end{array}$} & \multicolumn{2}{|c|}{$\begin{array}{c}\text { Normothermic } \\
\text { CPB }(n=28)\end{array}$} & \multirow{2}{*}{$\begin{array}{c}\text { Difference } \\
\text { (normothermic- } \\
\text { hypothermic) } \\
\end{array}$} & \multirow{2}{*}{$\begin{array}{c}\text { Ratio* } \\
\text { (normothermic/ } \\
\text { hypothermic) }\end{array}$} & \multirow[b]{2}{*}{$P$ valu } \\
\hline & Mean & SE & Mean & SE & & & \\
\hline \multicolumn{8}{|l|}{ Protein (logarithmic scale) } \\
\hline Baseline (mean, SD) & -2.28 & 0.61 & -2.14 & 0.71 & & & \\
\hline End of CPB & -2.42 & 0.16 & -2.16 & 0.17 & +0.26 & 1.30 & \\
\hline End of $\mathrm{CPB}+4 \mathrm{~h}$ & -2.23 & 0.11 & -2.52 & 0.12 & -0.29 & 0.75 & \\
\hline End of CPB $+24 \mathrm{~h}$ & -2.04 & 0.13 & -2.29 & 0.13 & -0.25 & 0.78 & \\
\hline \multicolumn{5}{|c|}{ Test for interaction between treatment and time } & & & .18 \\
\hline Overall treatment effect $\dagger$ & & & & & $-0.09(-0.30$ to 0.11$)$ & $0.91(0.74$ to 1.12$)$ & .38 \\
\hline \multicolumn{8}{|c|}{ Albumin (logarithmic scale) } \\
\hline Baseline (mean, SD) & 3.04 & 0.77 & 3.45 & 0.90 & & & \\
\hline End of CPB & 3.25 & 0.25 & 3.21 & 0.27 & -0.04 & 0.96 & \\
\hline End of $\mathrm{CPB}+4 \mathrm{~h}$ & 2.95 & 0.18 & 2.75 & 0.19 & -0.19 & 0.82 & \\
\hline End of CPB $+24 \mathrm{~h}$ & 2.89 & 0.15 & 2.73 & 0.15 & -0.17 & 0.85 & \\
\hline \multicolumn{5}{|c|}{ Test for interaction between treatment and time } & & & .91 \\
\hline Overall treatment effect $\dagger$ & & & & & $-0.13(-0.50$ to 0.23$)$ & $0.87(0.61$ to 1.26$)$ & .47 \\
\hline \multicolumn{8}{|l|}{ RBP (logarithmic scale) } \\
\hline Baseline (mean, SD) & 4.00 & 2.16 & 3.89 & 1.94 & & & \\
\hline End of CPB & 2.91 & 0.24 & 3.48 & 0.27 & $+0.57(-0.15$ to 1.28$)$ & $1.77(0.86$ to 3.61$)$ & .12 \\
\hline End of $\mathrm{CPB}+4 \mathrm{~h}$ & 4.78 & 0.27 & 4.21 & 0.28 & $-0.57(-1.15$ to 0.02$)$ & $0.57(0.32$ to 1.02$)$ & .056 \\
\hline End of $\mathrm{CPB}+24 \mathrm{~h}$ & 4.49 & 0.26 & 4.25 & 0.27 & $-0.24(-0.69$ to 0.22$)$ & $0.79(0.50$ to 1.25$)$ & .30 \\
\hline \multicolumn{5}{|c|}{ Test for interaction between treatment and time } & & & .032 \\
\hline \multicolumn{8}{|c|}{ NAG (logarithmic scale) } \\
\hline Baseline (mean, SD) & 1.47 & 1.00 & 1.63 & 1.30 & & & \\
\hline End of CPB & 1.79 & 0.22 & 1.96 & 0.24 & +0.17 & 1.19 & \\
\hline End of $\mathrm{CPB}+4 \mathrm{~h}$ & 2.33 & 0.19 & 2.09 & 0.20 & -0.24 & 0.79 & \\
\hline End of CPB $+24 \mathrm{~h}$ & 2.26 & 0.20 & 2.20 & 0.21 & -0.05 & 0.95 & \\
\hline \multicolumn{5}{|c|}{ Test for interaction between treatment and time } & & & .51 \\
\hline Overall treatment effect $\dagger$ & & & & & $-0.04(-0.45$ to 0.37$)$ & $0.96(0.64$ to 1.45$)$ & .85 \\
\hline \multicolumn{8}{|c|}{ RBP: creatinine ratio (logarithmic scale) } \\
\hline Baseline (mean, SD) & 3.257 & 1.687 & 2.596 & 1.973 & & & \\
\hline End of CPB & 1.606 & 0.228 & 1.765 & 0.242 & +0.159 & 1.17 & \\
\hline End of $\mathrm{CPB}+4 \mathrm{~h}$ & 4.080 & 0.269 & 3.879 & 0.286 & -0.201 & 0.82 & \\
\hline End of CPB $+24 \mathrm{~h}$ & 3.315 & 0.246 & 3.220 & 0.246 & -0.095 & 0.91 & \\
\hline \multicolumn{5}{|c|}{ Test for interaction between treatment and time } & & & .65 \\
\hline \multicolumn{5}{|c|}{ Overall treatment effect $\dagger^{\dagger}$} & $-0.046(-0.434$ to 0.342$)$ & $0.96(0.65$ to 1.41$)$ & .81 \\
\hline \multicolumn{8}{|c|}{ Albumin: creatinine ratio (logarithmic scale) } \\
\hline Baseline (mean, SD) & 1.91 & 0.72 & 2.17 & 0.98 & & & \\
\hline End of CPB & 1.80 & 0.32 & 1.24 & 0.33 & -0.55 & 0.58 & \\
\hline End of $\mathrm{CPB}+4 \mathrm{~h}$ & 2.61 & 0.16 & 2.14 & 0.17 & -0.47 & 0.62 & \\
\hline End of CPB $+24 \mathrm{~h}$ & 1.93 & 0.17 & 1.56 & 0.16 & -0.36 & 0.70 & \\
\hline \multicolumn{5}{|c|}{ Test for interaction between treatment and time } & & & .88 \\
\hline \multicolumn{5}{|c|}{ Overall treatment effect $\dagger$} & $-0.46(-0.87$ to -0.05$)$ & $0.63(0.42$ to 0.95$)$ & .028 \\
\hline \multicolumn{8}{|c|}{ NAG: creatinine ratio (logarithmic scale) } \\
\hline Baseline (mean, SD) & 0.31 & 0.88 & 0.18 & 1.19 & & & \\
\hline End of CPB & 0.29 & 0.23 & 0.38 & 0.25 & 0.09 & 1.09 & \\
\hline End of $\mathrm{CPB}+4 \mathrm{~h}$ & 1.82 & 0.22 & 1.45 & 0.23 & -0.37 & 0.69 & \\
\hline End of CPB $+24 \mathrm{~h}$ & 1.05 & 0.19 & 1.17 & 0.19 & -0.12 & 0.89 & \\
\hline Test for interaction betw & ent and ti & & & & & & .463 \\
\hline Overall treatment effect $\dagger$ & & & & & $-0.13(-0.58$ to 0.31$)$ & $0.86(0.56$ to 1.36$)$ & .55 \\
\hline
\end{tabular}

$C P B$, Cardiopulmonary bypass; $S E$, standard error; $S D$, standard deviation; $R B P$, retinal binding protein; $N A G, N$-acetyl- $\beta$-D-glucosaminidase. *Ratio of geometric means for skewed measures analyzed on the logarithmic scale. $\nmid$ Difference between the groups pooled over the postintervention time points as there was no evidence to suggest the difference varied across the time points studied. 


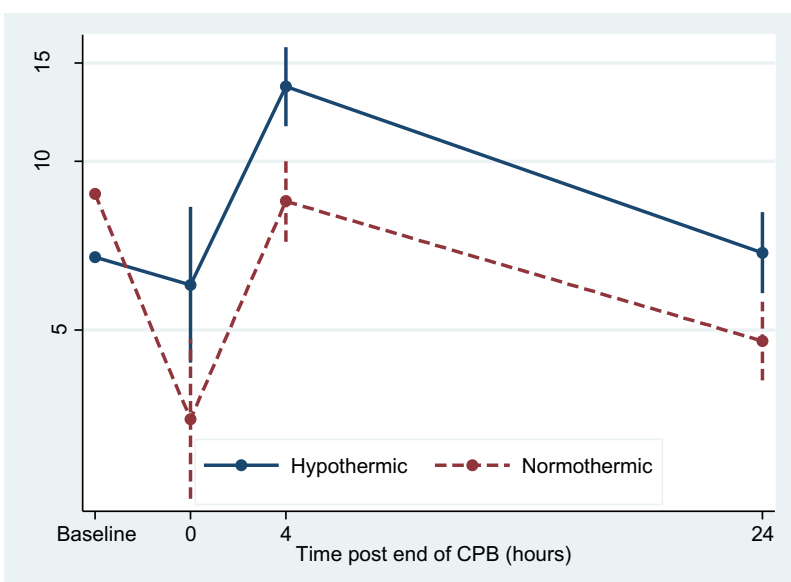

FIGURE 1. Time-related urinary changes in the albumin/creatinine in the hypothermic (-) and normothermic (-- -) groups. $C P B$, Cardiopulmonary bypass.

In the normothermic group, we observed a trend toward lower levels of NAG and albumin $(-14 \%$ and $-37 \%$, respectively) when expressed as a urinary creatinine ratio as well as lower serum creatinine and urea concentrations compared with the hypothermic group (Table 3 and Appendix E1). With the exception of albumin, these differences did not reach statistical significance but might indicate a degree of organ injury that is exacerbated by the cooling and rewarming process in the hypothermic group. Boodhwani and associates ${ }^{17}$ recently demonstrated that rewarming from mild hypothermia and the longer CPB time were predictors of renal dysfunction in adults undergoing coronary artery bypass grafting. Similar findings were reported by Kourliouros and colleagues, ${ }^{18}$ who identified reduced arterial perfusion temperature as an independent risk factor for renal injury in patients undergoing coronary artery bypass grafting. Animal studies ${ }^{17}$ have suggested that the kidney,

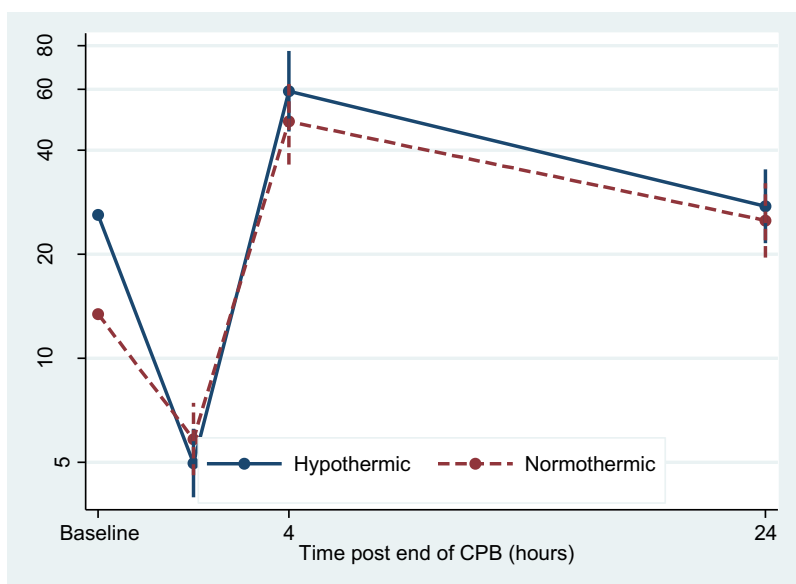

FIGURE 2. Time-related urinary changes in the RBP/creatinine in the hypothermic (-) and normothermic (--) groups. $C P B$, Cardiopulmonary bypass; $R B P$, retinal binding protein.

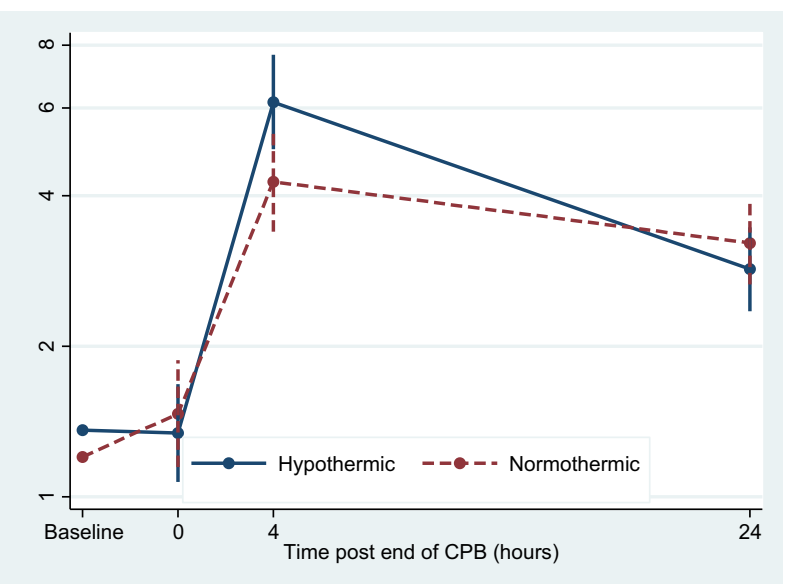

FIGURE 3. Time-related urinary changes in the NAG/creatinine in the hypothermic (-) and normothermic (--) groups. $C P B$, Cardiopulmonary bypass; $N A G, N$-acetyl- $\beta$-D-glucosaminidase.

with its high perfusion, rewarms even more rapidly than the brain, and renal temperatures likely exceed the temperatures monitored clinically during rewarming, causing a hyperthermia-induced exacerbation of injury. It is also interesting to note that other studies have demonstrated a higher incidence of neurocognitive deficits ${ }^{19}$ and myocardial reoxegenation injury in patients rewarmed from hypothermic CPB. ${ }^{10}$

The protective effects of hypothermia on organ function in the setting of ischemic injury have been previously demonstrated in animal models. In rodent models of renal ischemia and reperfusion, hyperthermia is associated with increased renal injury whereas hypothermia is protective. ${ }^{20,21}$ In the adult clinical setting, however, the benefits of hypothermia remain debated. Swaminathan

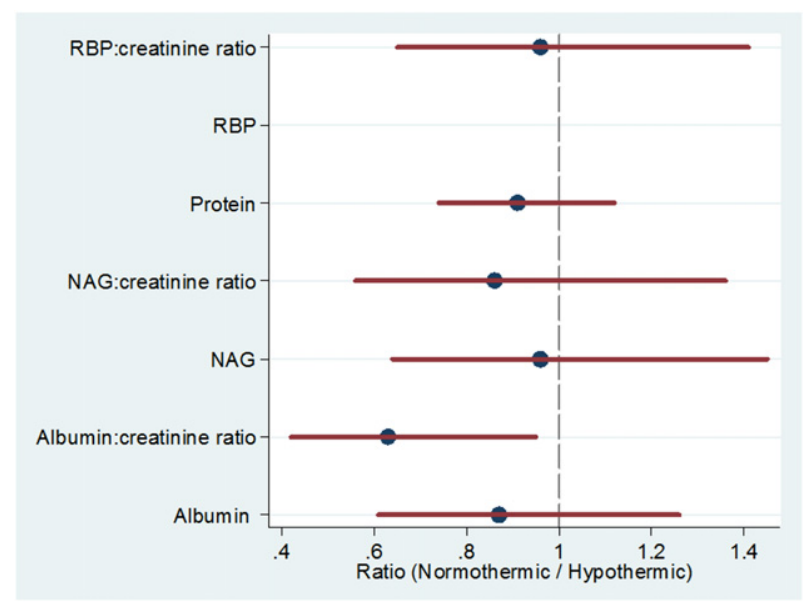

FIGURE 4. Treatment effects pooled over time. Treatment effect not shown for RBP as the effect varied with time $(P=0.32)$ Baseline and postintervention measures were modelled jointly on the logarithmic measurement scale. $R B P$, Retinal binding protein; $N A G, N$-acetyl- $\beta$-D-glucosaminidase. 
and colleagues ${ }^{22}$ examined the effects of warm $\left(35.5^{\circ} \mathrm{C}\right.$ $\left.36.5^{\circ} \mathrm{C}\right)$ versus cold $\left(28^{\circ} \mathrm{C}-30^{\circ} \mathrm{C}\right) \mathrm{CPB}$ management and found no difference in renal outcome between patient groups. Our group ${ }^{8}$ reported the results of a randomized trial that evaluated 3 temperature management protocols in adult patients undergoing myocardial revascularization and found no difference in renal markers of renal injury among the groups.

$\mathrm{CPB}$ perfusion temperature strategies and their effects on organ function are largely the result of work carried out in adult humans, and the conclusions drawn from these studies cannot necessarily be applied directly to infants or children. Recently, Durandy and Hulin ${ }^{23}$ provided an extensive retrospective clinical review of their experience with warm CPB in pediatric cardiac surgery. They compared more than 2000 patients who underwent cardiac surgery using either warm or cold CPB, concluding that normothermia was associated with improved early outcomes in pediatric patients without any adverse events. This study, however, was limited by its retrospective design, and they did not specifically analyze renal injury. These data, combined with our previously reported evidence on inflammatory response and myocardial injury, ${ }^{9}$ confirm the hypothesis that normothermic CPB is not responsible for any greater deleterious effects on renal function than hypothermic CPB in a "low-risk" patient population.

Acute kidney injury is still a common complication after CPB in children, with a reported incidence of approximately $5 \%$ to $20 \%,{ }^{24}$ and is associated with prolonged hospitalization, poor outcomes, and increased mortality. ${ }^{25}$ There is growing interest in the use of standardized criteria to define the occurrence of acute kidney injury in critically ill children, including those recovering from cardiac surgery. ${ }^{26}$ In our study population of low-risk patients, 2 patients, 1 in each group, had mild acute kidney injury develop, as defined by a $50 \%$ or greater increase in serum creatinine from baseline.

The importance of acute kidney injury combined with the limited evidence in support of the ideal CPB temperature during correction of a congenital heart defect in pediatric surgery makes the need for adequately sized randomized trials using clinical outcomes as primary end points even more urgent. In this study on relatively low-risk patients, normothermic CPB has been shown to be as safe as hypothermic CPB in terms of renal damage. It is not possible, at the moment, to generalize these findings to higher-risk patients (neonates or infants with longer CPB and ischemic times). Nevertheless, at our institution we are conducting a randomized controlled trial that is enrolling both lowrisk and higher-risk patients (neonates and infants not requiring hypothermic circulatory arrest) randomizing to normothermic or hypothermic $\mathrm{CPB}$, with the specific aim of looking at organ damage and clinical outcomes as primary end points.

\section{LIMITATIONS}

The study was powered to detect changes in biochemical markers but not in clinical outcome. It excluded neonates and patients with complex congenital heart diseases who are more likely to have postoperative renal dysfunction than patients included in the trial and patients with preexisting renal dysfunction, who are at highest risk of postoperative renal dysfunction. These patient groups stand to benefit most from a nephroprotective intervention. Also, we used 3 specific markers of tubular and glomerular injury. There are other markers available commercially that could have been used, and the combination of all these markers together might give us a more comprehensive picture of the renal damage in these patients.

\section{CONCLUSIONS}

In infants and children requiring correction of simple congenital heart defects, normothermic CPB is associated with similar renal injury compared with hypothermic $\mathrm{CPB}$. This is the first randomized trial evidence of the impact of normothermic CPB on renal function and contributes to the accumulating evidence of the safety of this technique in pediatric heart surgery.

We thank Mark Ginty, Svitlana Korolchuk, and Simon Bays for performing the biochemical analyses, Christine MacFadden for helping with data collection, and the pediatric nursing staff for their support.

\section{References}

1. Edmunds LH. Inflammatory and immunological response to cardiopulmonary bypass. In: Jonas RA, Elliot MJ, eds. Cardiopulmonary bypass in neonates, infants and young children. Oxford: Butterworth-Heinemann; 1994. p. 225-41.

2. Wagner FM, Schiller W, Dilg G, Depner C, Welz A, Lacour-Gayet F. Direct visualization of the influence of normothermic as opposed to hypothermic cardiopulmonary bypass on the systemic microcirculation in neonatal pigs. Cardiol Young. 2001;11:532-8.

3. Anttila V, Hagino I, Zurakowski D, Lidov HG, Jonas RA. Higher bypass temperature correlates with increased white cell activation in the cerebral microcirculation. J Thorac Cardiovasc Surg. 2004;127:1781-8.

4. Corno AF, von Segesser LK. Is hypothermia necessary in paediatric cardiac surgery? Eur J Cardiothorac Surg. 1999;15:110-1.

5. Taylor KM, Morton IJ, Brown JJ, Bain WH, Caves PK. Hypertension and renninangiotensin system following open heart surgery. J Thorac Cardiovasc Surg. 1977;74:840-5.

6. Singh AK, Feng WC, Bert AA, Rotenberg FA. Warm body, cold heart surgery: clinical experience in 2817 patients. Eur J Cardiothorac Surg. 1993;7:225-9.

7. Ip-Yam PC, Murphy S, Baines M, Fox MA, Desmond MJ, Innes PA. Renal function and proteinuria after cardiopulmonary bypass: the effects of temperature and mannitol. Anesth Analg. 1994;78:842-7.

8. Regragui IA, Izzat MB, Birdi I, Lapsley M, Bryan AJ, Angelini GD. Cardiopulmonary bypass perfusion temperature does not influence perioperative renal function. Ann Thorac Surg. 1995;60:160-4.

9. Caputo M, Bays S, Rogers CA, Pawade A, Parry A, Suleiman M-S, et al. The effects of normothermic and hypothermic cardiopulmonary bypass on myocardial injury, oxidative stress, and inflammatory response in pediatric open-heart surgery: a prospective randomized study. Ann Thorac Surg. 2005;80:982-8.

10. Caputo M, Mokhtari A, Gorhbel M, Rogers CA, Wolf A, Chen Q, et al. The effects of normoxic versus hyperoxic cardiopulmonary bypass on oxidative stress and inflammatory response in cyanotic pediatric patients undergoing open cardiac surgery: a randomized controlled trial. J Thorac Cardiovasc Surg. 2009; 138:206-14. 
11. Han WK, Waikar SS, Johnson A, Betensky RA, Dent CL, Devarajan P, et al. Urinary biomarkers in the early diagnosis of acute kidney injury. Kidney Int. 2008; 73:863-9.

12. El-Gamel A, Yonan N, Keevil B, Nicholls S, Smith KJ, Campbell C, et al. Measurement of microalbumin and retinol binding protein in cardiac and lung transplant recipients. Transplant Proc. 1995;27:1969-72.

13. Heinegard D, Tiderstrom G. Determination of serum creatinine by a direct colorimetric method. Clin Chim Acta. 1973;43:305-10.

14. Vaidyaa VS, Bonventrea JV, Ferguson MA. Biomarkers of acute kidney injury. In: McQueen CA, ed. Comprehensive toxicology. 2nd ed. New York, NY: Elsevier; 2010;7:197-211.

15. Che M, Xie B, Xue S, Dai H, Qian J, Ni Z, et al. Clinical usefulness of novel biomarkers for the detection of acute kidney injury following elective cardiac surgery. Nephron Clin Pract. 2010;115:66-72.

16. Tang ATM, El-Gamel A, Keevil B, Yonan N, Deiraniya AK. The effect of "renaldose" dopamine on renal tubular function following cardiac surgery: assessed by measuring retinol binding protein (RBP). Eur J Cardiothorac Surg. 1999;15:717-22.

17. Boodhwani M, Rubens FD, Wozny D, Nathan HJ. Effect of mild hypothermia and rewarming on renal function after coronary artery bypass grafting. Ann Thorac Surg. 2009;87:489-95.

18. Kourliouros A, Valencia O, Phillips SD, Collinson PO, van Besouw JP, Jahangiri M. Low cardiopulmonary bypass perfusion temperatures are associated with acute kidney injury following coronary artery bypass surgery. Eur J Cardiothorac Surg. 2010;37:704-9.

19. Nathan HJ, Wells GA, Munson JL, Wozny D. Neuroprotective effect of mild hypothermia in patients undergoing coronary artery surgery with cardiopulmonary bypass: a randomized trial. Circulation. 2001;104(12 Suppl 1):I85-91.

20. Zager RA, Gmur DJ, Bredl CR, Eng MJ. Degree and time sequence of hypothermic protection against experimental ischemic acute renal failure. Circ Res. 1989; 65:1263-9.

21. Delbridge MS, Shrestha BM, Raftery AT, Al Nahas AM, Haylor JL. The effect of body temperature in a rat model of renal ischemia-reperfusion injury. Transplant Proc. 2007;39:2983-5.

22. Swaminathan M, East C, Phillips-Bute B, Newman MF, Reves JG, Smith PK, et al. Report of a substudy on warm versus cold cardiopulmonary bypass: changes in creatinine clearance. Ann Thorac Surg. 2001;72:1603-9.

23. Durandy I, Hulin S. Intermittent warm blood cardioplegia in the surgical treatment of congenital heart disease: clinical experience with 1400 cases. $J$ Thorac Cardiovasc Surg. 2007;133:241-6.

24. Kist-van Holthe tot Echten JE, Goedvolk CA, Doornaar MBME, van der Vorst MMJ, Bosman-Vermeeren JM, van der Heijden AJ, et al. Acute renal insufficiency and renal replacement therapy after pediatric cardiopulmonary bypass surgery. Pediatr Cardiol. 2001;22:321-6.

25. Fleming F, Bohn D, Edwards H, Cox P, Geary D, McCrindle BW, et al. Renal replacement therapy after repair of congenital heart disease in children. $J$ Thorac Cardiovasc Surg. 1995;109:322-31.

26. Moffett BS, Goldstein SL, Adusei M, Kuzin J, Mohan P, Mott AR. Risk factors for postoperative acute kidney injury in pediatric cardiac surgery patients receiving angiotensin-converting enzyme inhibitors. Pediatr Crit Care Med. $2011 \mathrm{Feb}$ 10 [Epub ahead of print].

\section{Discussion}

Dr Richard G. Ohye (Ann Arbor, Mich). Congratulations, Dr Caputo and colleagues, for completing this trial.

I have 2 questions. As background, I think, the majority of us either do use or would feel very comfortable using normothermia in these straightforward operations with short or limited bypass times. What is the applicability to other cases that are more complex or that have longer bypass times? How may your data be applicable to neonates and more complex operations?

What was the reason for excluding neonates? Do you think that there is anything unique in their anatomy or physiology that may make these data applicable or not applicable?

Similarly, for more complex operations with longer bypass times, did you look at interactions between with bypass time and your outcomes that may show a greater or lesser effect at longer bypass times? It is those more complex operations in which these data may be more applicable.

My second question relates to your graphs, which consistently show a suggestion of a benefit for normothermia, although not statistically significant. Are you willing to speculate that normothermia might not only be worse, but might be beneficial compared with moderate hypothermia?

Dr Caputo. The reason we excluded neonates to start with was that, as in many other units, we were using hypothermia routinely, and to start the trial, we decided that for neonates we were not comfortable using normothermia.

The trial actually is still ongoing, because the second part of this trial will look at clinical outcomes, and the sample size for that is around 300 patients. For that we are excluding only patients who require hypothermic circulatory arrest. For example, we are now doing switches with normothermia for sure.

In terms of the effect of CPB time on these markers, we did not look specifically at the relationship and it is probably worthwhile doing that.

Dr Ohye. Are you willing to commit that normothermia may actually be beneficial compared with hypothermia?

Dr Caputo. Personally, I feel much more comfortable with normothermia, because I really believe that cooling and rewarming are actually detrimental for several organs, and I think the kidney is one of them.

Dr Constantine Mavroudis (Cleveland, Ohio). I wonder about the rate of myocardial rewarming during cardioplegic arrest during normothermic CPB caused by collateral flow or organ proximity to the heart. Do you plan to use myocardial temperature measurements in the future? In addition, in retrospect, did you notice with your normothermic group that the cardioplegia administration did not last as long as determined by immergence of electrical activity? Was there evidence of myocardial dysfunction after the operation? I think most people would use hypothermia not only for flow reasons but also to protect against myocardial rewarming. What are your thoughts about these issues?

Dr Caputo. Yes, we did look at the heart, and this was actually published a couple years ago. When we looked at markers of ischemia-reperfusion injury and reoxygenation injury in these 2 groups, we noticed that the normothermic group had less, for example, troponin I or 8-isoprostane release. Again, we do not believe that there are detrimental effects on the heart. On the contrary, in terms of reoxygenation injury, we might believe that normothermic CPB was beneficial.

In the same study we did evaluate the inflammatory response of the 2 techniques, and there was no difference. I am pretty confident that normothermia is safe for the heart. In fact, there is now evidence from groups in Paris using warm plegia, even though these are retrospective analyses, but they achieve quite good outcomes.

Dr Tara Karamlou (Seattle, Wash). I have 2 quick questions: First, can you briefly talk about your protocol regarding ultrafiltration? Did you use modified ultrafiltration in both groups equally? I wonder whether some of the markers that you are measuring could be affected by the use of modified ultrafiltration, especially in the short term. 
Second, was this study adequately powered and are we sure this is not just a statistical type II error, since you found no difference in many of your outcome measures?

Dr Caputo. We did not use modified ultrafiltration in these patients because they were not neonates. Normally we tend to use modified ultrafiltration in patients weighing below $5 \mathrm{~kg}$, so they did not receive ultrafiltration. Also, we measured the hematocrit of all these patients.

Dr Karamlou. Thus even if you were not using modified ultrafiltration, what was the perfusion strategy in terms of using filtration during the bypass times?

Dr Caputo. These patients specifically were not subjected to filtration during bypass, and the hematocrit was the same at all the time points for the 2 groups. We did measure the hematocrit levels.

Also, the renal function was actually in the urine, so the main markers are expression of the glomerular damage and tubular damage in the urine according to the glomerular filtration rate. That is the reason we looked at the ratio between the markers and the creatinine in the urine.

Please remind me of the second question.

Dr Karamlou. The second question was about power.

Dr Caputo. Yes, the power for these markers was based on our previous experience, and the sample size calculation was done on the area under the curve of these markers previously measured in similar studies. Thirty patients for each group was power enough to detect a difference there.

Dr Mark H. D. Danton (Glasgow, United Kingdom). Did you have any patients who were cyanotic in this group? One could consider that if there were cyanotic patients with hypothermia, the collateral flow may be increased as the systemic vasoconstriction takes place with hypothermia. Therefore, you may have a difference, you may have better perfusion to the kidneys and the end organs with normothermic bypass with cyanotic patients.

Dr Caputo. Yes, this is possible. Unfortunately, in this series, there are very few cyanotic patients. The reason is that this was clashing with another trial in which we were particularly studying cyanotic patients and reoxygenation injuries. So unfortunately, I cannot answer that question, but it is something we will look at in the future, specifically targeting cyanotic patients.

Dr Emile A. Bacha (New York, NY). What was the temperature of your cardioplegia?

Dr Caputo. It was cold blood cardioplegia in this series, so $4^{\circ} \mathrm{C}$.

Dr Bacha. At $4{ }^{\circ} \mathrm{C}$ ?

Dr Caputo. Yes, standard.

Dr Bacha. What kind of flows were you running?

Dr Caputo. These patients were at $2.5 \mathrm{~L}$.

Dr Bacha. I assume the same flows in both groups.

Dr Caputo. Yes. 
APPENDIX E1. Additional biochemical markers

\begin{tabular}{|c|c|c|c|c|c|c|}
\hline & \multicolumn{2}{|c|}{ Hypothermic CPB $(n=31)$} & \multicolumn{2}{|c|}{ Normothermic CPB $(n=28)$} & \multirow{2}{*}{$\begin{array}{c}\text { Difference } \\
\text { (normothermic-hypothermic) }\end{array}$} & \multirow[b]{2}{*}{$P$ value } \\
\hline & Mean & SE & Mean & SE & & \\
\hline \multicolumn{7}{|l|}{ Phosphate (mmol/L) } \\
\hline Baseline (mean, SD) & 1.49 & 0.39 & 1.49 & 0.37 & & \\
\hline Post-op & 1.44 & 0.06 & 1.38 & 0.06 & $-0.07(-0.09$ to 0.23$)$ & .42 \\
\hline \multicolumn{7}{|l|}{ Calcium (mmol/L) } \\
\hline Baseline (mean, SD) & 2.34 & 0.13 & 2.34 & 0.13 & & \\
\hline Post-op & 2.34 & 0.02 & 2.33 & 0.02 & $-0.01(-0.04$ to 0.06$)$ & .73 \\
\hline \multicolumn{7}{|l|}{ Magnesium (mmol/L) } \\
\hline Baseline (mean, SD) & 1.07 & 0.23 & 1.09 & 0.20 & & \\
\hline Post-op & 0.85 & 0.02 & 0.85 & 0.01 & $-0.003(-0.04$ to 0.03$)$ & .86 \\
\hline \multicolumn{7}{|l|}{ Glucose (mmol/L) } \\
\hline Baseline (mean, SD) & 4.88 & 1.04 & 4.66 & 0.67 & & \\
\hline Cross-clamp removal & 6.64 & 0.27 & 5.58 & 0.29 & -1.06 & \\
\hline Crossclamp removal $+30 \mathrm{~min}$ & 7.23 & 0.27 & 6.33 & 0.29 & -0.89 & \\
\hline Crossclamp removal $+2 \mathrm{~h}$ & 7.28 & 0.37 & 6.88 & 0.39 & -0.40 & \\
\hline Crossclamp removal $+6 \mathrm{~h}$ & 7.64 & 0.35 & 7.29 & 0.37 & -0.35 & \\
\hline Crossclamp removal $+24 \mathrm{~h}$ & 6.20 & 0.26 & 6.26 & 0.25 & +0.06 & \\
\hline \multicolumn{5}{|c|}{ Test for interaction between treatment and time } & & .20 \\
\hline Overall treatment effect & & & & & $-0.53(-1.10$ to 0.04$)$ & .07 \\
\hline \multicolumn{7}{|l|}{ Hematocrit $(\%)$} \\
\hline Baseline (mean, SD) & 35.6 & 5.35 & 35.9 & 4.69 & & \\
\hline Crossclamp removal & 26.6 & 0.44 & 25.5 & 0.46 & -1.09 & \\
\hline Crossclamp removal $+30 \mathrm{~min}$ & 29.5 & 0.62 & 29.3 & 0.66 & -0.15 & \\
\hline Crossclamp removal $+6 \mathrm{hrs}$ & 33.9 & 0.78 & 33.0 & 0.82 & -0.94 & \\
\hline Cross-clamp removal $+24 \mathrm{~h}$ & 33.2 & 0.79 & 32.8 & 0.77 & -0.45 & \\
\hline \multicolumn{5}{|c|}{ Test for interaction between treatment and time } & & .47 \\
\hline Overall treatment effect & & & & & $-0.66(-1.93$ to 0.61$)$ & .30 \\
\hline \multicolumn{7}{|l|}{ Lactate $(\mathrm{mmol} / \mathrm{L})$} \\
\hline Baseline (mean, SD) & 0.98 & 0.32 & 1.05 & 0.41 & & \\
\hline Crossclamp removal & 0.96 & 0.06 & 0.97 & 0.06 & +0.01 & \\
\hline Crossclamp removal $+30 \mathrm{~min}$ & 1.11 & 0.06 & 1.10 & 0.06 & -0.01 & \\
\hline Cross-clamp removal $+2 \mathrm{~h}$ & 1.06 & 0.10 & 1.31 & 0.11 & +0.25 & \\
\hline Crossclamp removal $+6 \mathrm{~h}$ & 1.24 & 0.11 & 1.28 & 0.12 & +0.04 & \\
\hline Crossclamp removal $+24 \mathrm{~h}$ & 1.03 & 0.09 & 1.21 & 0.10 & +0.18 & \\
\hline \multicolumn{5}{|c|}{ Test for interaction between treatment and time } & & .25 \\
\hline Overall treatment effect & & & & & $+0.094(-0.06$ to 0.25$)$ & .23 \\
\hline \multicolumn{7}{|l|}{ Serum creatinine $(\mu \mathrm{mol} / \mathrm{L})$} \\
\hline Baseline (mean, SD) & 58.2 & 11.9 & 60.7 & 11.4 & & \\
\hline End of CPB & 60.0 & 2.35 & 57.3 & 2.39 & -2.74 & \\
\hline End of $\mathrm{CPB}+24 \mathrm{~h}$ & 62.9 & 2.37 & 58.3 & 2.38 & -4.56 & \\
\hline End of $\mathrm{CPB}+48 \mathrm{~h}$ & 61.2 & 2.33 & 59.2 & 2.44 & -2.03 & \\
\hline End of $\mathrm{CPB}+72 \mathrm{~h}$ & 61.9 & 2.67 & 62.8 & 2.88 & 0.93 & \\
\hline \multicolumn{5}{|c|}{ Test for interaction between treatment and time } & & .46 \\
\hline Overall treatment effect & & & & & $-2.10(-6.51$ to 2.31$)$ & .34 \\
\hline \multicolumn{7}{|l|}{ Urea $(\mathrm{mmol} / \mathrm{L})$} \\
\hline Baseline (mean, SD) & 4.62 & 1.27 & 4.55 & 1.38 & & \\
\hline End of CPB & 4.59 & 0.21 & 4.53 & 0.21 & -0.05 & \\
\hline End of $\mathrm{CPB}+24 \mathrm{~h}$ & 5.73 & 0.30 & 5.42 & 0.30 & -0.31 & \\
\hline End of $\mathrm{CPB}+48 \mathrm{~h}$ & 6.08 & 0.28 & 5.05 & 0.31 & -1.03 & \\
\hline End of $\mathrm{CPB}+72 \mathrm{~h}$ & 5.45 & 0.29 & 5.16 & 0.34 & -0.28 & \\
\hline \multicolumn{5}{|c|}{ Test for interaction between treatment and time } & & .18 \\
\hline Overall treatment effect & & & & & $-0.42(-0.88$ to 0.04$)$ & .072 \\
\hline \multicolumn{7}{|l|}{ Sodium $(\mathrm{mmol} / \mathrm{L})$} \\
\hline Baseline (mean, SD) & 137.6 & 1.87 & 137.7 & 2.05 & & \\
\hline End of CPB & 139.7 & 0.47 & 139.1 & 0.46 & -0.60 & \\
\hline
\end{tabular}


APPENDIX E1. Continued

\begin{tabular}{|c|c|c|c|c|c|c|}
\hline & \multicolumn{2}{|c|}{ Hypothermic CPB $(n=31)$} & \multicolumn{2}{|c|}{ Normothermic CPB $(n=28)$} & \multirow{2}{*}{$\begin{array}{c}\text { Difference } \\
\text { (normothermic-hypothermic) }\end{array}$} & \multirow[b]{2}{*}{$P$ value } \\
\hline & Mean & SE & Mean & SE & & \\
\hline End of $\mathrm{CPB}+24 \mathrm{~h}$ & 138.3 & 0.61 & 137.5 & 0.64 & -0.80 & \\
\hline End of $\mathrm{CPB}+48 \mathrm{~h}$ & 136.1 & 0.61 & 135.8 & 0.66 & -0.28 & \\
\hline End of $\mathrm{CPB}+72 \mathrm{~h}$ & 135.6 & 0.60 & 134.8 & 0.70 & -0.78 & \\
\hline \multicolumn{3}{|c|}{ Test for interaction between treatment and time } & & & & .91 \\
\hline Overall treatment effect & & & & & $-0.61(-1.87$ to 0.64$)$ & .33 \\
\hline \multicolumn{7}{|l|}{ Potassium (mmol/L) } \\
\hline Baseline (mean, SD) & 4.04 & 0.30 & 3.98 & 0.17 & & \\
\hline End of CPB & 4.21 & 0.07 & 4.13 & 0.07 & -0.08 & \\
\hline End of $\mathrm{CPB}+24 \mathrm{~h}$ & 4.33 & 0.11 & 4.19 & 0.11 & -0.14 & \\
\hline End of $\mathrm{CPB}+48 \mathrm{~h}$ & 4.04 & 0.09 & 3.96 & 0.01 & -0.08 & \\
\hline End of $\mathrm{CPB}+72 \mathrm{~h}$ & 3.94 & 0.13 & 3.64 & 0.16 & -0.31 & \\
\hline \multicolumn{3}{|c|}{ Test for interaction between treatment and time } & & & & .67 \\
\hline Overall treatment effect & & & & & $-0.15(-0.33$ to 0.03$)$ & .096 \\
\hline
\end{tabular}

